\title{
ANAESTHETIC MANAGEMENT OF A HUGE ORAL LYMPHANGIOMA IN A NEONATE
}

\author{
Laxmi Narayana Anpuram¹, Kousalya Chakravarthy², Sunil Kumar Cherukuri³, Srinivas Reddy Nalagandla ${ }^{4}$, \\ Radha Ramana Murthy konda ${ }^{5}$
}

${ }^{1}$ Assistant Professor, Department of Anaesthesia, Niloufer Hospital for Women \& Children, RedHills, Lakidikapool, Hyderabad. ${ }^{2}$ Assistant Professor, Department of Anaesthesia, Niloufer Hospital for Women \& Children, RedHills, Lakidikapool, Hyderabad. ${ }^{3}$ Assistant Professor, Department of Anaesthesia, Niloufer Hospital for Women \& Children, RedHills, Lakidikapool, Hyderabad. ${ }^{4}$ Assistant Professor, Department of Anaesthesia, Niloufer Hospital for Women \& Children, RedHills, Lakidikapool, Hyderabad. 5 Professor,Department of Anaesthesia, Niloufer Hospital for Women \& Children, Red Hills, Lakidikapool, Hyderabad.

ABSTRACT: Lymphangiomas are commonly located in head and neck. They are congenital benign haemartomas of the lymphatic system. The most common location of intra oral lymphangiomas is the dorsum of the tongue. The lymphangiomas are amicable to surgical excision. Large oral lymphangiomas can decrease the already small mouth opening in the neonates and cause difficulty in mask ventilation, laryngoscopy and intubation. The postoperative challenges include laryngospasm and airway obstruction compounded by the large tongue and the airway odema caused by the surgical manipulations. Providing a safe anesthesia in such challenging cases necessitate awareness of the anesthetic complications and necessary steps to prevent them. In this case report we present a case of large oral lymphangioma in a newborn and discuss the peri operative and anesthetic management.

KEYWORDS: Lymphangioma, Airway Management, Pediatrics, Anesthesia.

HOW TO CITE THIS ARTICLE: Laxmi Narayana Anpuram, Kousalya Chakravarthy, Sunil Kumar Cherukuri, Srinivas Reddy Nalagandla. Radha Ramana Murthy konda. "Anaesthetic Management of a Huge Oral Lymphangioma in a Neonate". Journal of Evolution of Medical and Dental Sciences 2015; Vol. 4, Issue 89, November 05; Page: 15493-15495,

DOI: $10.14260 /$ jemds/2015/2215.

INTRODUCTION: Lymphangiomas are hamartomatous, congenital malformations of the lymphatic system. The incidence of lymphangiomas has been reported to range from 1.2 to 2.8 per 1000 newborns.[1] $50 \%$ of the lymphangiomas will be diagnosed at birth and $90 \%$ of them are diagnosed by $2 \mathrm{yrs}$ of age. $75 \%$ of the cases were found in the head and neck, $15 \%$ are in axillary region. [2] Here we are reporting a huge lymphangioma of the tongue occupying the entire oral cavity.

CASE REPORT: A just born term neonate weighing $3 \mathrm{kgs}$ was referred to the emergency department of pediatrics, Niloufer Hospital Hyderabad in view of large oral tumor. Antenatal History of mother was uneventful. The mother was Primi, non-consanguineous marriage, No history of co morbid conditions. Mother underwent Emergency LSCS for PROM (Premature Rupture of Membranes) under subarachnoid block. Liquor was clear, 5 minute APGAR of the Baby 7,9,9. The obstetrician noticed an Oral swelling. Baby was referred to Paediatric Department Niloufer Hospital immediately.

At the time of admission baby was warm, pink, afebrile, stridor was present, no cyanosis. Vitals were noted. HR 140/min, RR 42/min. CVS first and second heart sounds were heard, no murmurs appreciated. Lungs were clinically clear at the time of admission. Abdomen was soft.

Local Examination revealed a round bluish colored oral mass, occupying the oral cavity measuring about $5 \mathrm{~cm}$ in diameter.

Financial or Other, Competing Interest: None.

Submission 13-10-2015, Peer Review 14-10-2015,

Acceptance 21-10-2015, Published 05-11-2015.

Corresponding Author:

Dr. Kousalya Chakravarthy,

Flat 504, C-Block, Amsri Central Court,

Old Lancer Lines, Secunderabad-500025.

E-mail: dr.kausi.c@gmail.com

DOI: $10.14260 /$ jemds/2015/2215.
The mass was cystic in consistency soft and compressible. There were no other swellings in the body.

Surgical excision of the mass was planned after initial stabilization and investigations. Pre-operative stabilization included nursing in prone position, prevention of hypoglycaemia, prevention of dehydration and prophylactic antibiotics.

Pre op evaluation: On physical examination inspiratory stridor was present with mild retraction of the chest wall. X- Ray chest, Ultra sound and CECT were advised to assess the size and extent of the mass and to detect the potential for airway compromise and to avoid soft tissue trauma during intubation.

USG Neck: Was suggestive of multiloculated cystic lesion? Cystic hygroma? Giant Ranula

CECT Head \& Neck: Evidence of large well defined multiloculated hypodense lesion measuring $4 \times 4.5 \mathrm{~cm}$ noted in submandibular region extending into the floor of mouth posteriorly up to base of tongue. Oropharyx, nasopharynx, larynx-normal. Normal study of Brain.? Lymphangioma? Cystic hygroma

As a part of pre-operative assessment of airway the oral cavity was lubricated with lubricating jelly on a finger. Tumour was found to be compressible. Gentle laryngoscopy could be done. The plan of Anaesthesia included inhalation induction, spontaneous ventilation and nasal intubation.

ANESTHETIC MANAGEMENT: Intraoperative monitoring was done with ECG, Pulse oxymetry, Neonatal NIBP. Baby was preoxygenated with $100 \%$ oxygen. Premedication was given with IV Glycopyrrolate, ondansetron $300 \mu \mathrm{g}$ and Fentanyl $3 \mu \mathrm{g}$. Induced with 3\% Sevoflurane. Laryngoscopy and Magills assisted nasal intubation tried but could not be accomplished due to narrow space in the oral cavity. 
Modification of the position by placing a role under the shoulder helped in aligning naso pharyngo laryngeal axis. Anaesthetic planes were deepened with propofol $7 \mathrm{mg}$ IV. Nasotracheal intubation was done successfully with 3.0 ETT. Bilateral air entry checked, ETT secured with plaster and NDNMBD-Atracurium $0.5 \mathrm{mg} / \mathrm{kg}$ was given. Anaesthesia was maintained with N20 /02: 50:50 and 1.0\% Sevoflurane.

Subtotal excision of lymphangioma from floor of mouth up to anterior wall of pharynx was done. Stay suture was taken on tip of tongue to prevent tongue fall. $150 \mathrm{ml}$ of Balanced Salt Solution was given as intraoperative fluid supplementation. Post-surgery baby recovered completely from anaesthesia. Tone regained eye opening was present. Reversal was given with neostigmine $150 \mu \mathrm{g}$ and glycopyrrolate. Extubation was done guardedly after complete clinical reversal under close observation for desaturation. Initially stable baby started desaturating after 20 minutes and was immediately reintubated.

Baby was shifted to NICU for elective ventilation with CPAP. On the Ist POD baby was extubated, advised to nurse in prone position, vitals monitored and maintained. Stay suture on tongue removed on $3^{\text {rd }}$ POD and shifted to the ward.

DISCUSSION: Oral lymphangiomas rare in occurrence and they are frequently located at the anterior $2 / 3$ of dorsum of the tongue followed by palate, buccal mucosa, gingiva, and lips. Congenital lymphangiomas may occur in association with Down's syndrome, Turner's syndrome Noonan's syndrome, Cardiac anomalies and Fetal hydrops.[3] The differential diagnosis includes oral tumours like ranula, cystic hygroma and other head and neck tumours. ${ }^{[4,5,6]}$ CT or MRI should be done prior to extablish the extent of involvement.[7] Carbon dioxide laser has been used in some cases but surgical excision still is considered the treatment of choice. ${ }^{[8,9]}$

\section{Anesthetic Management Of Oral Lymphangioma:,[10]}

The pediatric and neonatal airway management has intrinsic problems peculiar to that age group.[11] This is further compounded by the huge oral mass. Options of anesthesia for oral lymphangiomas can be:

1. Awake intubation with intact reflexes-The potential disadvantages of this technique is difficulty in securing the airway in struggling neonate, potentially traumatic technique, and stress induced physiological changes like increase in blood pressure, heart rate, oxygen consumption and intracranial pressures.

2. Inhalation Induction with spontaneous breathing-Is a better technique in experienced hands. This has the advantages of having the baby in spontaneous respirations, without the undue disadvantages of inducing stress

3. Invasive techniques like tracheostomy are not suitable for neonates but can be resorted to in special situations.

Anesthesia related problems are frequently encountered in view of extension of the lymphangioma into pharynx or thorax, hemorrhage during resection, involvement of pre-tracheal region, post-operative respiratory obstruction and concurrent congenital anomalies.
POST OP COMPLICATIONS: Airway edema due to surgical manipulations can occur. Laryngospasm should be anticipated and preventive measures should be taken.[11] Other complications include edema of the tongue, respiratory obstruction, infection, intra cystic hemorrhage, injuries to neighboring structures (Facial nerve, recurrent laryngeal nerve, internal jugular vein parotid duct,pharynx, $9^{\text {th }}, 10^{\text {th }}, 11^{\text {th }}, 12^{\text {th }}$ cranial nerves).[12] The resultant airway edema may necessitate post-operative ventilator support.

CONCLUSION: Anaesthetic management of neonate with lymphangioma of oral cavity requires thorough knowledge of the disease and experience in paediatric airway management. A good preoperative preparation and optimization of the patient along with a definitive plan of the mode of anaesthesia is necessary. Difficulty in securing the airway, Intra operative blood loss and post-operative airway obstruction should be anticipated. Extubation should be planned only in the fully awake infants. The patients should be in NICU as there is high risk of re intubation. A thorough preop preparation, intra operative and post-operative care is the key to successful management of oral tumours in infants.

\section{REFERENCES:}

1. D L Grasso, G Pelizzo1, E Zocconi, J Schleef. Lymphangiomas of the head and neck in children. Acta Otorhinolaryngol Ital 2008;28:17-20.

2. Prashant K Minocha, Lakhan Roop, Rambachan Persad. Cases of Atypical Lymphangiomas in Children. Hindawi Publishing Corporation, Case Reports in Pediatrics. Volume 2014, Article ID 626198, 6 pages. http://dx.doi.org/10.1155/2014/626198

3. KK Tiwari, C Sharma, V Chaturvedi, R Tangar, A Ameta. Oral Cystic Lymphangioma with Severe Respiratory Distress in a Neonate. IOSR Journal of Dental and Medical Sciences (IOSR-JDMS) Volume 13, Issue 5 Ver. I. (May. 2014), PP 25-27 www.iosrjournals.org

4. Verma G. Ranula: A Review of Literature. Arch CranOroFac Sc 2013;1(3):44-49.

5. B Mirza, L Ijaz, M Saleem, M Sharif, A Sheikh. Cystic Hygroma: An Overview. J Cutan Aesthet Surg. 2010 SepDec; 3(3): 139-144.

6. Ragesh K.P, R. S. Chana, P. K. Varshney, M. Naim. Head and neck masses in children: A clinicopathological study. Indian Journal of Otolarngology and Head and Neck Surgery. 2002 Oct-Dec; 54(4): 268-271.

7. L Stănescu, E. F. Georgescu,C Simionescu, I Georgescu. Lymphangioma of the oral cavity. Romanian Journal of Morphology and Embryology 2006, 47(4):373-377.

8. G T S Aciole, J M S Aciole, L G P Soares, N R S Santos, J N Santos, A L B Pinheiro. Surgical Treatment of Oral Lymphangiomas with CO2 Laser: Report of Two Uncommon Cases. Braz Dent J (2010) 21(4): 365 -369.

9. S Sunil, D Gopakumar, B S Sreenivasan. Oral lymphangioma - Case reports and review of literature. Contemp Clin Dent. 2012 Jan-Mar; 3(1): 116-118.

10. B M Thompson, J O Welna, J L Kasperbauer, J M. Van Ess, M E. Shirk Marienau. Childhood airway manifestations of lymphangioma: A case report. AANA Journal. August 2004;72(4): 280-283. 
11. S. Chattopadhyay, A. Rudra, S. Sengupta. Laryngospasm in Paediatric Anaesthesia: A Review. International Journal of Anesthesiology Research, 2013, 1, 97-104.
12. Kamal A M Hassanein. Outcome of Surgical excision of cervico facial lymphatic malformations in children: A Prospective Study. Egyptian Journal of Surgery Vol. 31, No. 2, April 2012.

\begin{tabular}{|c|c|c|}
\hline \multicolumn{3}{|c|}{ Investigations at the Time of Admission } \\
\hline \multirow{2}{*}{1} & $\begin{array}{c}\text { CBC Haemoglobin } \\
\text { TLC } \\
\end{array}$ & $\begin{array}{c}15.5 \text { gms } \% \\
12,200 \\
1.2 \mathrm{Lacs}\end{array}$ \\
\hline 2 & Platelets & $\mathrm{A}+$ \\
\hline 3 & S. Creatinine & 0.8 \\
\hline 4 & RBS & $40 \mathrm{mg} / \mathrm{dl}$ \\
\hline \multirow{2}{*}{5} & Coagulation profile : PT/INR & $15.1 / 1.1$ \\
& APTT & 32 \\
\hline 6 & Chest X-Ray & Normal study \\
\hline
\end{tabular}

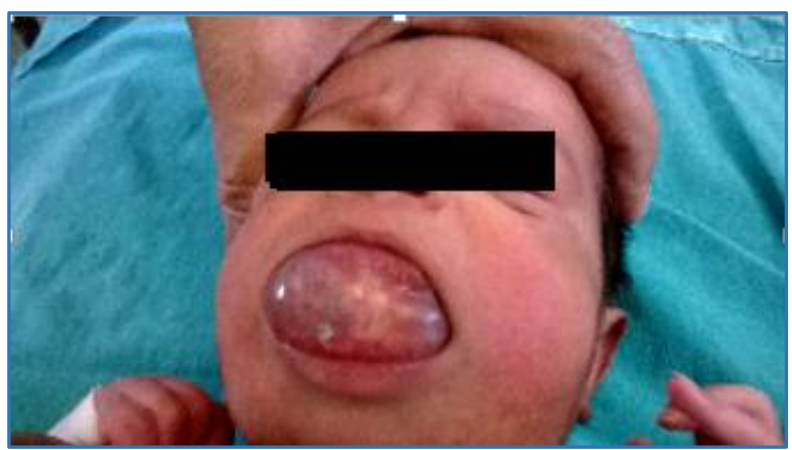

Fig. 1: Oral Lymphangioma at the time of presentation

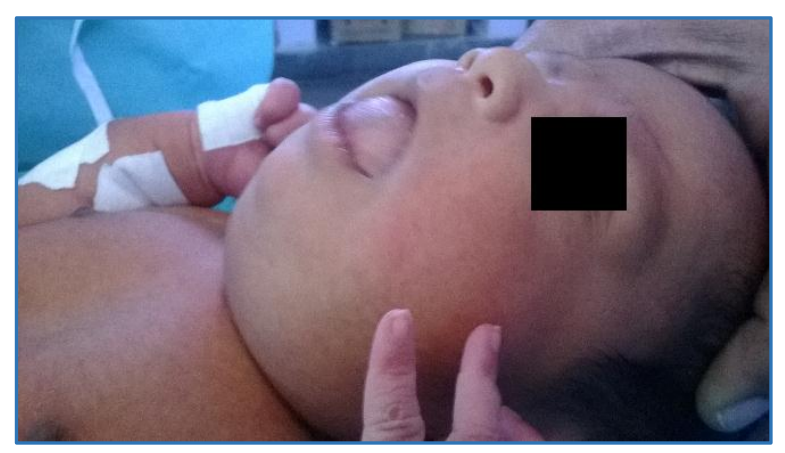

Fig. 2: At the time of Induction Difficult Airway

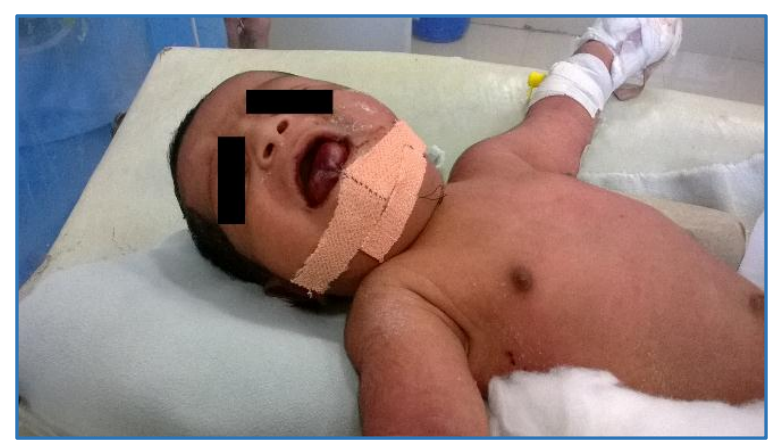

Fig. 3: Ist POD after extubation 